\title{
Posttraumatic thoracic anterior epidural hematoma together with Posttraumatic T11-12 Disc Herniation: A case report
}

\author{
Hakan Kayali* and Hüseyin Sataloglu \\ Department of Neurosurgery of a Private Hospitals Group in Ordu, Turkey
}

\begin{abstract}
This article presents a 66 year old female admitted to emergency department with increasing back pain, and serious monoparesis on left lower extremity and urinary and fecal incontinance increasing day by day after fall from the tree one week ago. T11 hemangioma, anterosuperior partial corpus fracture of T12, T11-12 disc herniation and thoracic spinal epidural hematoma in the anterior epidural space were diagnosed by Magnetic Resconance Imaging (MRI). The patient was operated immediately with using neuromonitorisation. After surgery and three weeks rehabilitation programme the patient discharged with full recovery.

Spinal epidural hematomas (SEHs) are rare clinical disorders that might result in permanant neurological deficits and even if death when left untreated. Posttraumatic, thorasic and especially anterior located epidural hematomas are more rare in whole spinal epidural hematomas. Evacuation of the spinal epidural hematoma by the early surgical decommpression may recovery some neurological deficits and particularly vital cord functions. Especially if a patient has some progressive neurological deficits increasing day by day after trauma, SEH must be considered.
\end{abstract}

\section{Introduction}

Spontaneous SEH (SSEH) is a rare cause of back pain in the emergency department (estimated incidence of approximately 0.1 per 100,000 patients per year) [1]. The classic clinical presentation is acute onset of severe, often radiating, back pain followed by signs and symptoms of nevre root and/or spinal cord compression, which develops minutes to days later [2-4]. SSEH occurs in all age groups, but most frequently after fourth decade of life [5]. The most common localizations in adults are the cervicothoracic and thoracolumbar junctions [6]. Posttraumatic SEH with abnormal neurologic findings is very uncommon [7].

\section{Case report}

A 66 year- old female admitted to emergency department with increasing back pain, and serious monoparesis on left lower extremity and urinary and fecal incontinance (Frankel D2) increasing day by day after fall from the tree one week ago. T11 hemangioma, anterosuperior partial corpus fracture of T12, T11-12 central disc herniation most probably due to trauma and thoracic spinal epidural hematoma in the anterior epidural space lies between T10 and L1 vertebraes were diagnosed by MRI. Most thickness of epidural hematoma was calculated $6 \mathrm{~mm}$ at T11 level (Figures 1 and 2).

The patient was operated immediately with these clinical and radiological findings and evacuation of thorasic anterior SEH and T1112 microdiscectomy were performed by the left costotransversectomy and transpedicular approach and partial corpectomy on the left lateral side of T11 and T12 vertebraes. Although there was no active bleeding from T11 hemangioma, peroperatoire vertebroplasty also was performed to prevent probably late hemorrhages and postoperative pain. Neuromonitorisation was also used in the operation to prevent the secondary injuries may be depend on the surgery. The rehabilitation programme has been started in the postoperative fifth day for the patient and neurological findings recoveried to (Frankel 3 ) in the early postoperative period. After three weeks rehabilitation programme the patient discharged with full recovery.

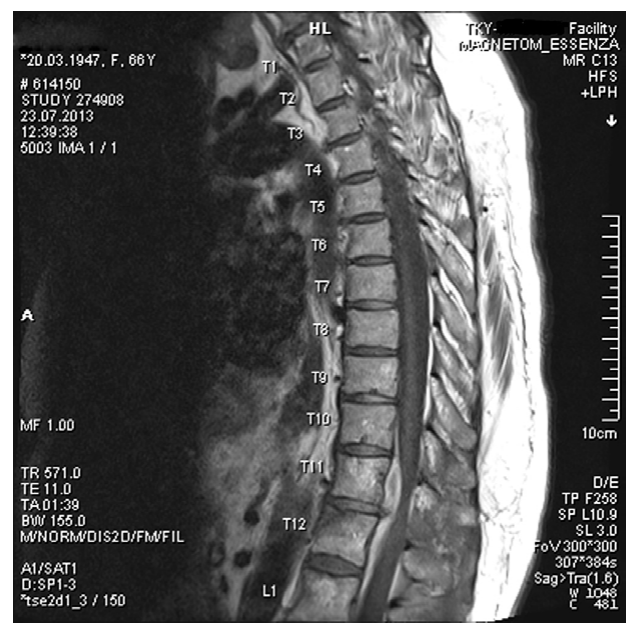

Figure 1. T1 weighted MRI shows the anterior located spinal epidural hematoma spreads along T10-L1 four vertebra levels, hemangioma in corpus of T11, anterosuperior partial corpus fracture of T12 and T11-12 disc herniation most probably due to trauma.

Correspondence to: Hakan Kayali MD, Department of Neurosurgery, Özel İstanbul Bölge Hastanesi, Atatürk Cad. No: 123 Sancaktepe - İstanbul, Turkey, Tel: +90 50585503 37; Fax: +90 21662120 10; E-mail: hakankayali@hotmail.com

Key words: spinal epidural hematoma, thoracic disc herniation, surgical treatment Received: March 05, 2017; Accepted: March 21, 2017; Published: March 24, 2017 


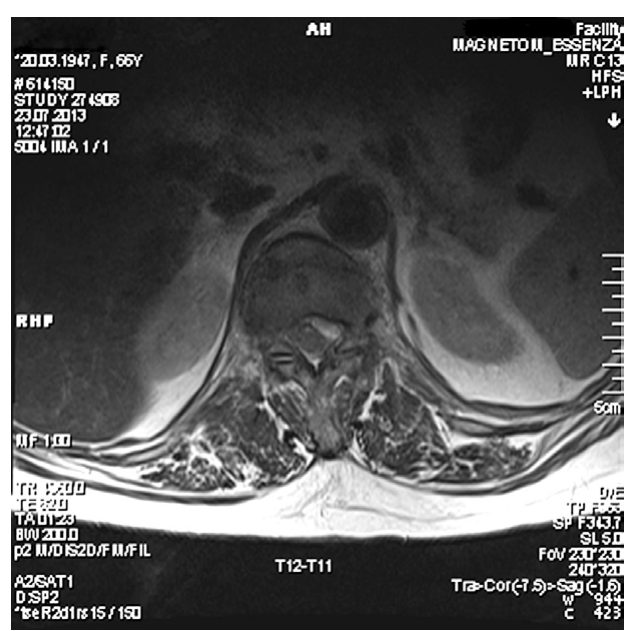

Figure 2. Axial T1 weighted MRI of the same case.

\section{Discussion}

The pathogenesis of SEH is not clear and risk factors have not been established. Risk factors for SEH include hemophilia A and B, coagulopathy with abnormal anticoagulants, intraspinal vascular malformation, spinal hemangioma, trauma and iatrogenic injury. Some authors suggest the fragility of the epidural venous plexus as the cause of bleeding. Vascular malformations were proven in some cases, but their involvement is uncertain [8-10]. Gundry and Heithoff reported an association between epidural hematoma and rupture of a deep disc. This led them to argue that a SEH would result from the tearing of adjacent fragile epidural veins to the annulus fibrosus or nucleus pulposus [11]. In this case no observation an active bleeding from the hemangioma is located corpus of T11 vertebra during the surgery, no autoimmun or hematologic diseses or anticoagulant using and the presence of a central disc herniation at T11-12 level most probably due to trauma, supports Gundry and Heithoff's argument.

Hematomas are usually located posterior to the spinal cord, which is consistent with the anatomical location of the venous plexus [5,12]. In one large literature survey of case reports of spinal hematomas of any causes, Kreppel et al. [12] described that almost $75 \%$ of spinal hematomas are located posterior to the spinal cord. Ventral hematomas, as in this case, represented ony $5 \%$ of all cases. Other authors have also described this posterior predominance $[5,13,14]$.

The clinical features of SEH are variable. There is severe spinal pain for some minutes to some days, the symptoms of spinal cord compression may include ascending numbness, loss of leg sensory function, caudaequina syndrome and paraplegia or tetraplegia $[1,8,14]$.

The differential diagnosis for SEH includes migration of a slipped disc, metastatic tumor, epiduritis and rarely a neural cyst [9]. So accurate neuroradiologic confirmation of the correct diagnosis is mandatory. In the past, lumbar myelography and computed tomography scanning were used for diagnosis. However, these techniques are nonspesific, may not provide the accurate lenght of the hematoma and may produce false-negative findings [14,15]. Currently, spinal MRI has replaced these techniques as the initial diagnostic tool for SEH. MRI is non invasive, accurate and can demonstrate the localisation and length of the hematoma as well as the effects on the spinal cord $[1,5,14]$. In this case the lenght of SEH was imagined by MRI, along four vertebral levels and in contrast usual, located anterior of the spinal cord.

As a result, post-traumatic, thorasic and especially anterior located
SEHs are very rare. Patients with suspected SEH with neurologic dysfunction must be evaluated with MRI. Evacuation of the spinal epidural hematoma by the early surgical decompression may recovery some neurologic deficits and particularly vital cord functions. Particularly if a patient has some proggressive neurologic deficits increase day by day after trauma SEH must be considered. The results of decompressive surgery are fine and neuromonitorisation during the surgery has an effective protective value both of the patient and surgeon.

Footnote: Because of the hospital which was performed this surgery is a private hospital, its' brand name was not used in this article but, although authors resigned from this hospital and continue to work in different cities and in different hospitals, ethically the name of the city Ordu, where was performed the surgery was used.

\section{Conflicts of interest disclosure}

The authors received no financial support for this study. They have no personal, financial, or instutional inerets in any of the materials or methods described in this article.

\section{References}

1. Holtas S, Helling M, Löntoft M (1996) Spontaneous spinal epidural hematoma: findings at MR imaging and clinical correlation. Radiology 199: 409-413. [Crossref]

2. Liu WH, Hsieh CT, Chiang YH, Chen GJ (2008) Spontaneous spinal epidural hematoma of thoracic spine: a rare case report and review of literature. Am J Emerg Med 26: 384. [Crossref]

3. Lannum S, Stratton J (2009) Spontaneous epidural hematoma of the thoracic spine in a 17-year-old adolescent boy: a case report. Am J Emerg Med 27: 628.[Crossref]

4. Miller JB, Khalsa G, Vohra T (2010) Spontaneous spinal epidural hematoma presenting as flank pain and constipation. Am J Emerg Med 28: 536.[Crossref]

5. Liao CC, Lee ST, Hsu WC, Chen LR, Lui TN, et al. (2004) Experience in the surgical management of spontaneous spinal epidural hematoma. J Neurosurg 100: 38-45. [Crossref]

6. Groen RJ, Ponssen H (1990) The spontaneous spinal epidural hematoma. A study of the etiology. J Neurol Sci98: 121-138.[Crossref]

7. Jae-Ryong Cha, Ki-Bong Park, Sang-Hun Ko (2011) Posttraumatic lumbar epidural hematoma with neurology: Report of 1 case. Asian Spine J5: 130-132.

8. Lederle FA, Cundy KV, Farinha P, McCormick DP (1996) Spinal epidural hematoma associated with warfarin therapy. Am J Med 100: 237-238.[Crossref]

9. Nagata K, Ariyoshi M, Ishibashi K, Hashimoto S, Inoue A (1998) Chronic lumba epidural hematoma in a patient who had spondylolisis at the third lumbar vertebra: report of rare case involving a seventeen-year-old adolescent. J Bone Joint Surg Am80: 1515-20. [Crossref]

10. Henderson RD, Pittock SJ, Piepgras DG, Wijdicks EF (2001) Acute spontaneous spinal epidural hematoma. Arch Neurol 58: 1145-1146.[Crossref]

11. Gundry CR, Heithoff KB (1993) Epidural hematoma of the lumbar spine: 18 surgically confirmed cases. Radiology 187: 427-431.[Crossref]

12. Kreppel D, Antoniadis G, Seeling W (2003) Spinal hematoma: a literature survey with meta-analysis of 613 patients. Neurosurg Rev 26: 1-49.[Crossref]

13. Groen RJ, van Alphen HA (1996) Operative treatment of spontaneous spinal epidural hematomas: a study of the factors determining postoperative outcome. Neurosurgery 39: 494-509. [Crossref]

14. Alexiadou-Rudolf C, Ernestus RI, Nanassis K, Lanfermann H, Klug N (1998) Acute nontraumatic spinal epidural hematomas: an important differential diagnosis in spinal emergencies. Spine 23:1810-1813. [Crossref]

15. Avrahami E, Tadmor R, Ram Z, Feibel M, Itzhak Y (1989) MR demonstration of spontaneous acute epidural hematoma of the thoracic spine. Neuroradiology31: 89-92. [Crossref]

Copyright: $(\mathrm{C} 2017$ Kayali $\mathrm{H}$. This is an open-access article distributed under the terms of the Creative Commons Attribution License, which permits unrestricted use, distribution, and reproduction in any medium, provided the original author and source are credited. 